\title{
Hibridismo como forma televisiva impura: vozes dissonantes em The Voice Brasil
}

\section{Rosana de Lima Soares}

Professora livre-docente no Departamento de Jornalismo e Editoração e no Programa de PósGraduação em Meios e Processos Audiovisuais da Escola de Comunicações e Artes da Universidade de São Paulo (USP), realizou pesquisa de pós-doutorado no King's College Brazil Institute (Londres/Inglaterra). É pesquisadora do MidiAto - Grupo de Estudos de Linguagem: Práticas Midiáticas.

E-mail: rolima@usp.br

\section{Andrea Limberto}

Mestre e doutora em Ciências da Comunicação pela Escola de Comunicações e Artes da USP, realizou pesquisa de pós-doutorado na mesma instituição, intitulada "Nos Termos da \#Interdição" (bolsista Fapesp). É pesquisadora do MidiAto - Grupo de Estudos de Linguagem: Práticas Midiáticas.

E-mail: andrealimberto@gmail.com
Resumo: Este artigo pretende recuperar a experiência recente, cada vez mais valorizada e profusa, dos formatos audiovisuais híbridos no sentido de investigar possibilidades para o protagonismo discursivo de distintos atores sociais. Em termos gerais, trataremos de alguns aspectos constituintes do reality show The Voice Brasil, apontando espaços de presença/ausência de sujeitos não hegemônicos em programas televisivos; as práticas discursivas como espaços de intertextualidade e heterogeneidade, comumente referidas nos debates sobre convergências midiáticas; as múltiplas identidades do sujeito em meio à proliferação de imagens; as políticas da representação e os regimes de visibilidade presentes nas mídias, especialmente aqueles relacionados a figuras de alteridade, estabelecendo tensões entre as narrativas do mesmo e do outro nelas apresentadas.

Palavras-chave: Práticas Midiáticas; Narrativas Audiovisuais; Hibridismo; Visibilidade; Reality TV.

\section{Hybridism as impure television form: dissonant voices in The Voice Brasil}

Abstract: This article recovers recent hybrid audiovisual experiences, which are more privileged and profuse than ever, considering if they enable discursive protagonism of diverse social actors. In general terms, we focus on some of the founding aspects of the singing reality show The Voice Brasil and the presence or absence of non-hegemonic subjects in television shows; discourse as intertextual and heterogeneous practices, usually present in the debates on media convergence; the multiple identities of the subjects within proliferation of images; the politics of representation and the visibility regimes, especially those related to figures of alterity, establishing tension between narratives of the self and the other.

Keywords: Mediatic Practices; Audiovisual Narratives; Hibridism; Visibility; Reality TV. 
Este artigo observa a presença de formatos midiáticos híbridos, avaliando as possibilidades por eles abertas para o protagonismo discursivo de distintos atores sociais. Propomos que tais formatos apresentam abertura que se produz na combinação entre gêneros (como disrupção genérica), costura temática própria (como variação temática) e experimentação de visibilidades dos sujeitos neles posicionados (como alternativa às representações identitárias fechadas). Do ponto de vista teórico, trilhar o caminho dos hibridismos é assumir que as práticas discursivas, nos três âmbitos mencionados, são espaços de intertextualidade e heterogeneidade, como demonstraremos a seguir.

Nesse sentido, defendemos que produções híbridas, pela combinação das características mencionadas, ensejam o debate sobre a possibilidade de articular visibilidades e também posicionamentos dos sujeitos representados. Não miramos quaisquer sujeitos, mas aqueles com potencial transgressivo, ou seja: os que podemos considerar, de algum modo, como culturalmente estigmatizados. Eles balizam a construção de imagens que poderíamos incluir na ideia de popular midiático, que Serelle (2014) identifica como o evento disperso de uma guinada: "A guinada popular na cultura midiática brasileira sobrepõe-se à ascensão, nas últimas décadas de nossa vida social, de uma 'nova classe trabalhadora', representada em participantes de reality shows, em perfis e vídeos da internet, em programas jornalísticos e outros, de entretenimento, cuja programática é centralizar a periferia" (SERELLE, 2014: 46).

Em seu artigo "A guinada dos populares: mídia e vida social no Brasil", o autor afirma que a guinada midiática dos populares é um fenômeno presente em diversos países, adquirindo contornos particulares quando tratamos do caso brasileiro, em que a emergência midiática e a emergência de classe social se encontram. Serelle elege como um dos exemplos o programa televisivo The Voice Brasil, exibido pela Rede Globo, que será objeto também deste artigo.

Como hipótese, consideramos que, além da celebrização dos participantes para que vençam precariedades sociais por meio de seus perfis biográficos instituindo narrativa de sucesso rumo ao estrelato -, haveria hoje maior espaço ao protagonismo de pessoas comuns, que não apenas performatizam um enredo construído pelo programa mas nele inscrevem sua própria trajetória. Ainda assim, a pergunta sobre os modos de construção dessa representação permanece como questão produtiva na análise desse programa. Trata-se, portanto, de indagar se as políticas da representação empreendidas demandam novos regimes de visibilidade, em que a diversidade se instaura de modo transgressor, rompendo a domesticação aparentemente pressuposta nas imagens. Além disso, voltamonos para a questão dos hibridismos audiovisuais a partir desse gênero televisivo, no qual depoimentos em primeira pessoa, testemunhos de familiares e amigos, cenas do cotidiano e dados biográficos, além da presença de amigos e conhecidos nos bastidores do programa, compõem narrativa que oscila entre referencialidade e ficcionalidade, tanto do ponto de vista da produção como da recepção.

Temos como interesse específico observar de que modo tais produções híbridas fazem emergir, por essa brecha intermitente, também diversidade de vozes representativas que se tornam de alguma forma perceptíveis. Elas intentam apresentar realidades tangíveis e tais formatos são tanto mais contundentes quanto maior a tentativa de aproximação com realismos possíveis nos campos comuns da cultura e, em decorrência, de suas possibilidades de representação do "outro". Instauramos, assim, tal perspectiva no desafio de nos mantermos na pluralidade dessas realidades e no multifacetamento dos sujeitos apresentados.

Como percurso possível, mas no qual essas ideias não se esgotam, faremos rápida incursão pelos formatos da reality TV (cf. SOARES, 2015), pensando os "realismos contemporâneos" e chegando aos formatos específicos dos reality shows. Nos modos de construção da realidade dos quais se imbui a reality $T V$, acreditamos que 
esteja presente a incorporação de alteridade desafiadora e distante. Perguntamonos, então, se esse "outro" pode falar nesse e em outros gêneros, se sua diferença pode ser de fato contemplada e acolhida. Especificamente, olharemos alguns exemplos em The Voice Brasil (que teve sua terceira temporada em 2014), pensando-o enquanto locus privilegiado para entender tais fenômenos.

No ano em questão, The Voice Brasil consolidava seu formato na grade televisiva nacional, confirmando sua exibição nas noites de quinta-feira ( $22 \mathrm{~h} 30)$ ao invés de aos domingos (tentativa realizada na primeira temporada). Tal consolidação refletiuse na garantia de maior audiência nessa faixa horária e também em singularidades no contexto da produção. Na terceira edição do programa concorreram muitos candidatos que haviam feito parte da história também marcante do reality show musical Ídolos (SBT e Record), criando interessante relação entre as personagens das emissoras. Vale ressaltar que, independentemente disso, os candidatos mais bem-sucedidos, inclusive aqueles que tomamos como exemplo neste artigo, não tinham esse histórico televisivo explicitado. A história deles foi construída, de outro modo, no âmbito das narrativas de superação e de posições identitárias polêmicas, gerando modos de representação - e processos de identificação - pautados pela possibilidade de deslocamento discursivo e reconhecimento social. Desde a emblemática e polêmica recusa do cantor sertanejo indígena Yuri Maison, na primeira temporada do reality, não só a aceitação, mas a incorporação de distintos sujeitos da voz nacional ampliou-se.

A temporada de 2014 que analisamos é privilegiada no sentido de consolidar um formato televisivo que confirma também a predileção pelos candidatos "populares". The Voice Brasil encontra-se atualmente em sua sexta temporada (2017) evem, desde então, reforçando a valorização de candidatos que representem a diversidade e as vozes do Brasil, inclusive reafirmando textualmente, na fala de seus técnicos, que temos uma voz popular, singular, impura e própria que deve ser apresentada.

Ao longo do artigo faremos um caminho que partirá da identificação dos hibridismos presentes em reality shows à visibilidade por eles propostas, nos termos de uma televisão que apela a certo tipo de realismo visando alcançar o reconhecimento por parte de seu público. Neles apresentamos o caso específico de The Voice Brasil, como dissemos, com alguns exemplos que nos possibilitam debater os modos de dar a ver esses sujeitos. E questionamos, por meio da noção de "subalternidade", a possibilidade mesma de presença da voz destes sujeitos ali representados, partindo de determinadas escolhas narrativas e configurando discursos mais ou menos estabilizados sobre eles.

Compreendemos como híbridos, inicialmente, traços que marcam produções culturais que se apresentam como mistura entre dois ou mais gêneros (ou formatos) conhecidos. Esse processo de hibridação pode envolver imbricações formais, estéticas, temáticas, narrativas em favor de uma produção de sentidos diferenciada em relação às anteriormente reconhecidas. Temos acompanhado o movimento crescente em direção a esse tipo de produção, cada vez mais frequente no cenário midiático contemporâneo. E destacamos, ainda que pontualmente, diversos autores que podem corroborar conosco nesse argumento, seja pelo caminho das convergências (cf. JENKINS, 2009), da cultura midiática (cf. KELLNER, 2001), da crítica literária (cf. SAID, 1995) ou da dialogia (cf. BAKHTIN, 2008), para citar alguns.

Mais particularmente, há também um percurso entre autores (clássicos ou contemporâneos) que têm pesquisado a estética do audiovisual não apenas no cinema, mas também na criação possibilitada pelas produções televisivas, buscando a inserção de seus gêneros, enredos e mudanças históricas na cultura (JOST, 2007; SILVERSTONE, 1994; WILLIAMS, 1975). Na passagem do olhar que mencionamos e pretendemos chegar, retomamos o trabalho de Robert Stam em 
artigo escrito originalmente em 1997, no qual o autor reforça o caráter intertextual das produções híbridas, tanto no quesito expressivo, quanto na abertura técnica:

${ }^{1}$ Do original: "The cinema, I would argue, is ideally equipped to express cultural and temporal hybridity. The cinema is temporally hybrid, first of all, in an intertextual sense, in that it 'inherits' all the art forms and millennia traditions associated with its diverse matters of expression. (The music or pictorial art of any historical period can be cited, or mimicked, within the cinema). But the cinema is also temporally hybrid in another, more technical sense. As a technology of representation, the cinema mingles diverse times and spaces; it is produced in one constellation of times and spaces, it represents still another (diegetic) constellation of times and places, and is received in still another time and space (theatre, home, classroom)".

\footnotetext{
${ }^{2}$ Do original: "If the historical world is a meeting place for the process of social exchange and representation in the interactive mode, the representation of the historical world becomes, itself, the topic of cinematic mediation in the reflexive mode. Rather than hearing the filmmaker engage solely in an interactive (participatory, conversational, or interrogative) fashion with other social actors, we now see or hear the filmmaker also engage in metacommentary, speaking to us less about the historical world itself, as in the expository and poetic or interactive and diaristic modes, than about the process of representation itself".
}

\begin{abstract}
Argumentamos que idealmente o cinema é preparado para expressar uma hibridação cultural e temporal. Em primeiro lugar, o cinema é temporalmente híbrido no sentido intertextual de que ele "herda" toda forma de arte e tradição milenar associada às suas materialidades expressivas. (A música ou a arte pictórica de qualquer período histórico pode ser referenciada ou mimetizada no cinema). Mas o cinema é também temporalmente híbrido num outro sentido mais técnico. Sendo uma tecnologia de representação, o cinema combina diferentes tempos e espaços; ele é produzido numa constelação de tempos e espaços e ainda representa uma outra constelação (diegética) de tempos e espaços, além de ser recebido ainda num outro tempo e espaço (a sala de cinema, em casa, a sala de aula). (STAM, 2015, s/p, tradução nossa) ${ }^{1}$
\end{abstract}

Nesse ambiente de aberturas presentes em produções que se oferecem e se conectam para além de si, não apenas em perspectiva narrativa, mas também interdiscursiva, falamos de hibridismos no plural, considerando que a variedade de combinações seja justamente aquilo que os identifica. A partir desse ponto, propomos três aspectos que marcam as produções híbridas em geral e que podem nos guiar no percurso. O primeiro é a valorização da intertextualidade; o segundo, a constituição de sua heterogeneidade; e o terceiro, como suas características afetam as possibilidades de construção de visibilidades dos sujeitos representados.

Uma das características valorizadas em relação às produções midiáticas é sua capacidade de incorporar e privilegiar aberturas intertextuais, e de fazer referência a formatos variados, incluindo, assim, diversas materialidades. Tais aberturas são dialógicas e, ao mesmo tempo, sempre tensionadas entre dois ou mais textos de origem. Em relação à heterogeneidade, podemos caracterizar a impureza de tais produções pois não se preocupam em responder diretamente a um cânone - ao menos não apenas a um deles. Enquanto a intertextualidade reverbera textos para além dos limites da obra, a heterogeneidade vê processo similar na composição de elementos considerados a ela intrínsecos. Nichols identifica, em relação a um modo de produção mais interativo, a possibilidade de encontro participativo, conversacional e interrogativo como forma de acesso ao outro:

\footnotetext{
Se o mundo histórico é um lugar de confluência para o processo de troca social e de representação no modo interativo, a representação do mundo histórico se torna ela mesma um tópico de mediação cinemática no modo reflexivo. Mais do que somente ouvir o cineasta se envolver num encontro interativo (participativo, conversacional ou interrogativo) com outros atores sociais, nós também o vemos ou ouvimos fazer um metacomentário, falando conosco menos sobre o mundo histórico em si, como nos modos expositivo e poético ou interativo e cotidiano, do que sobre o próprio processo de representação. (NICHOLS, 1991: 57, tradução nossa) ${ }^{2}$
}

Tal linha de pensamento nos estimula a definir uma obra por meio dos modos de sua articulação com outros formatos, mais do que por determinações de modelos genéricos estanques. No sentido inverso, essa mesma redução não ancorada em gêneros - mas a partir de traços genéricos - ajuda a reconstituir possíveis interstícios entre aparatos interpretativos, se estivermos dispostos a nos render à observação de suas características impuras. Assim, podemos abordar a questão dos hibridismos através da noção de gêneros (sejam documentais, ficcionais ou híbridos) e de uma teoria dos gêneros, nos termos propostos por Altman ao questionar sua utilização como forma de segurança teórica. Nesse sentido, o autor reforça a instabilidade e a incerteza de abordagens distintas: "O trabalho do teórico é ponderar sobre diferentes abordagens não exatamente para descartar posições insatisfatórias, mas tentando construir um modelo que inclua a relação 
${ }^{3}$ Do original: "The task of the theorist is then to adjudicate among conflicting approaches, not so much by dismissing unsatisfactory positions, but by constructing a model which reveals the relationship between differing critical claims and their function within a broader cultural context". entre diferentes demandas críticas e sua função dentro de um contexto cultural mais amplo" (ALTMAN, 1984: 6, tradução nossa). ${ }^{3}$

São os desafios às categorias genéricas que nos permitem tratar de hibridismos, levando-nos a considerá-las enquanto categorias dinâmicas, e não estanques, que respondem às mudanças na sociedade e se transformam de acordo com o impulso de hibridização das produções culturais de cada época. Além disso, gêneros podem ser entendidos em grandes chaves e nas combinações a partir delas, tanto no cinema, como na televisão. Vislumbramos, desse modo, a possibilidade de apropriações genéricas carnavalizadas - pilhagens e ressignificações (cf. SOARES, 2011) - que se revelam, por exemplo, na presença de um programa americano adaptado como programa brasileiro, guardando características globalizantes e, ao mesmo tempo, revelando elementos locais.

Assim, argumentamos que gêneros não são tipologias e constituem-se como práticas sociais, diferenciando-se apenas à medida que forem considerados uns em relação aos outros. Finalmente, podemos afirmar que, por estarem intimamente relacionados a contextos singulares, os gêneros conectam os campos da produção e da recepção, dando lastro aos contratos comunicacionais estabelecidos. Nesse sentido, eles mantêm diálogo constante com discursos hegemônicos, sejam de reforço ou de contestação, e resultam numa historicização do presente que embasa movimentos e mobilizações. Defendemos que, nessas aberturas, há apelo popular que favorece repensar e transformar seus modelos.

\section{A televisão representativa do popular midiático}

A televisão é, em sua especificidade, terreno fértil para que os hibridismos que estamos delineando se apresentem, por ser um meio popular e por estar desvinculada de muitos dos padrões estéticos demandados à produção artística. No entanto, configurando-se como meio massivo e apresentando o que é comum, há uma dificuldade em reconhecer estatuto valorizado do popular em suas interfaces com o midiático. Durante a realização da Mostra Internacional de Cinema de São Paulo, em 2014, o crítico Rodrigo Salem (2014), em resenha ao filme argentino Relatos selvagens, afirma: "Enquanto o cinema comercial brasileiro preocupa-se em copiar comédias americanas dos anos 1980, o argentino dá uma lição de como equilibrar pop e inteligência", contando com produção dos irmãos Almodóvar, conquistando a plateia em Cannes e batendo recordes de bilheteria em seu país. Ainda que a aceitação do público pudesse macular a qualidade do filme, Salem insiste em demarcar o campo cultuado do cinema dito "de autor" em detrimento de produções genéricas tidas como "comerciais", apontando o filme como "uma ideia simples e bem escrita que pode ensinar um pouco sobre a diferença entre pop e popularesco para nossa indústria de comédias globais".

A premissa da qual parte o jornalista para emitir sua opinião sobre o filme acaba por desqualificar obras recentes do cinema brasileiro, especialmente aquelas de apelo popular, potencial mercadológico e produção industrial. Nada muito diferente do que os preconceitos de gosto, classe e gêneros narrativos muitas vezes atribuídos à televisão, especialmente quando se aproxima daquilo que podemos definir como o "popular midiático". No caso da televisão, para além de distinções relacionadas à produção, vemos aquelas que dizem respeito ao lugar da recepção e do público, interligando os que assistem aos programas às características a eles atribuídas.

Em relação aos programas chamados popularescos, mais do que mostrar personagens comuns eles também se dirigem àqueles retratados em suas imagens, numa espécie de jogo que estabelece hierarquias culturais, sociais e políticas. Recentemente, como dissemos, podemos observar um alargamento dos sujeitos representados nesses programas, não apenas em termos de visibilidade midiática, mas também em termos da diversidade de gêneros e formatos nos quais são retratados, apontando para um profícuo campo de hibridismos audiovisuais. 
Se considerarmos os pactos comunicacionais propostos pelas mídias, a adesão da audiência televisiva e a resposta do público a determinados programas, veremos que o lugar da recepção nos processos de leitura e ressignificação nos auxilia na percepção de um movimento que, aparentemente, rompe uma rede pré-estabelecida, rearticulando os modos de construção da representação nesses programas. Complexos processos de identificação passam a operar para que o público se reconheça em determinados formatos e não em outros, autenticando e legitimando os modos pelos quais atores sociais ausentes passam a ser mostrados. Pessoas comuns, anônimos, minorias ocupam as telas em lugares anteriormente impensáveis, gerando, junto com audiência, outros modos de recepção e efeitos de sentidos guiados por estratégias que se utilizam da hibridização de gêneros e formatos.

Temos, portanto, novas políticas da representação que transformam lugares de invisibilidade social (não reconhecimento) e ampliam as fronteiras do imaginário (discursos circulantes), alterando os regimes de visibilidade instituídos. Essa heterogeneidade, em nossa perspectiva, é marcada pela presença de atores sociais não hegemônicos, ratificando a proposta de investigarmos espaços de presença/ ausência desses sujeitos, bem como pontos de redundâncias e ressonâncias de estigmas sociais em discursos televisivos.

Podemos argumentar que, em parte como efeito dos movimentos em favor da intertextualidade e da heterogeneidade das produções híbridas, tal desvio normativo pode gerar a apresentação de uma visibilidade variada e impura. Indagamos nesse caso, sobre aquilo que dela emerge enquanto possibilidade de representação dos sujeitos, de renovação estética e de deslizamento discursivo. Aumont (1995: 21) nos recorda que reagimos diante da realidade da imagem e daquilo que produz na inter-relação entre sujeitos. A visão de cada um é parcialmente afetada e enquadrada por esse ato coletivo, respondendo a um campo de visualidades recortadas:

\footnotetext{
O importante neste ponto é observar que reagimos diante da imagem fílmica como diante da representação muito realista de um espaço imaginário que aparentemente estamos vendo. Mais precisamente, como a imagem é limitada em sua extensão pelo quadro, parece que estamos captando apenas uma porção desse espaço. É essa porção de espaço imaginário que está contida dentro do quadro que chamaremos de campo.
}

Dessa forma, argumentamos que uma instância de alteridade pode erigirse de uma tentativa de vencer a distância entre "um" e "outro", a partir do reconhecimento possível entre eles. Ao mesmo tempo em que temos aproximação e movimento de familiaridade, ocorre também a marcação da singularidade, sua sedimentação em processos representacionais. Das diferentes posições ocupadas pelos sujeitos no tecido social surge, consequentemente, um campo midiaticamente ordenado de embates entre cada um e todos os outros, interpelando os limites da representação e alargando suas fronteiras. Podemos afirmar, portanto, que há reiteração de certos modos de interação, interferindo nos regimes de visibilidade e recobrindo a dinâmica percebida nos hibridismos audiovisuais.

A emergência de discursos hegemônicos ou contra-hegemônicos, sempre em disputa, opera por meio das formas consolidadas de construção da representação, constituindo terreno fértil para a problematização - comumente referida nos debates sobre as mídias - de novas posicionalidades do sujeito em meio à proliferação de imagens e, consequentemente, às transformações no imaginário social. Estabelece-se, assim, um desafio à conceituação das políticas da representação. Um dos caminhos que encontramos para estabelecer os contornos de tal desafio é considerá-las no escopo dos regimes de visibilidade, que deslocam 
os pontos de vista de um olhar a outro, entrevendo visadas sobre sujeitos visíveis. Tratamos, então, das visibilidades presentes nas mídias, especialmente aquelas relacionadas a figuras de alteridade, estabelecendo as tensões entre as narrativas do mesmo e do outro nelas apresentadas.

Não se trata, entretanto, de cruzar dados para buscar lugares ocupados por sujeitos antes ausentes ou silenciados, mas de traçar o regime de sujeitos que, de algum modo, se prendem à malha do visível. Um sujeito inexistente no discurso é diferente do que se encontra invisibilizado; este também se distingue daquele que, ainda que se mostre visível, não desempenha papel de protagonismo em suas narrativas. Estabelece-se, assim, jogo de posições/oposições entre visível e invisível, revelando mais do que polaridades ao delinear a concretude de ambos na composição e no efeito final sobre o campo ampliado do visível. Há ainda questão de estilo em relação à materialidade das imagens, ou de como elas se realizam não o que dizem, mas o que fazem e o que nos fazem fazer frente a elas. Samain (2014: 53), em relação aos trabalhos de Didi-Huberman, recupera que

as imagens não são apenas atos e fatos, mas ainda - na temporalidade que toda imagem carrega - lugares de memórias (lembranças, sobrevivências, ressurgências), revelações de tempos passados, de tempos presentes. Por vezes, até lugares de expectativas (esperanças, prefigurações de tempos que hão de vir, presságios, promessas, desejos).

Quais seriam, portanto, os deslocamentos a partir de diferentes políticas da representação, os momentos em que podemos vislumbrar, ainda que brevemente, um giro nos discursos circulantes? Pretendemos endereçar essa questão por meio da temática dos estigmas presentes em gêneros televisivos híbridos, especificamente aqueles em que se mesclam formas documentais e ficcionais, observando a variedade de uma espécie de realismo disperso. Mais do que categoria genérica densa e bem demarcada, notamos o espraiamento de seus traços em diferentes produções audiovisuais, marcadas por duas atitudes principais:

Simplificando bastante, e correndo o risco de caricaturar um pouco as posições de uns e de outros, é possível dizer que sempre existiram duas atitudes principais a propósito da representação fílmica, encarnadas por dois tipos de cineastas: André Bazin caracterizou os últimos, num texto célebre ("a evolução da linguagem cinematográfica"), como "os que acreditam na imagem" e "os que acreditam na realidade" - em outras palavras, os que fazem da representação um fim (artístico, expressivo) em si e os que a subordinam à restituição o mais fiel possível de uma suposta verdade, ou de uma essência, do real (AUMONT, 1995: 46).

Gostaríamos de recuperar a noção de que, nas oscilações entre as duas posições, articulam-se novos realismos por meio de pluralidades discursivas. Nesse sentido, estaríamos mais próximos do "outro" que queremos ver? Com Foster (1999: 130), podemos referenciar a ruptura causada por um sujeito emergente como sendo da ordem de "realismo traumático": "Podemos ler as imagens de 'Death in America' como sendo referenciais e simulacro, conectadas e desconectadas, afetivas e inefetivas, críticas e complacentes? Eu acredito que nós devemos fazer isso e podemos fazê-lo se as lermos de uma terceira maneira, nos termos de um

${ }^{4}$ Do original: "Can we read the 'Death in America' images as referential and simulacral, connected and disconnected, affective and affectless, critical and complacent? I think we must and we can if we read them in a third way, in terms of a traumatic realism". realismo traumático" (tradução nossa). ${ }^{4}$

A referência do autor se dá, nesse caso, em relação ao trabalho do artista plástico pop Andy Warhol. Em circuito divergente, ao considerarmos produções audiovisuais contemporâneas podemos nos perguntar se haveria, de fato, ampliação ou apenas reiteração dos modos de representação vigentes. Buscaremos iluminar esse debate observando a posição de diferentes sujeitos na produção televisiva atual. A proposta avança no sentido de identificar, nos 
${ }^{5}$ Nos canais abertos da televisão brasileira podemos citar um histórico da evolução destes programas desde 2002, incluindo os seguintes realities musicais: Popstar (SBT, duas temporadas, 2002 e 2003, lançando as bandas Rouge e $\mathrm{Br}^{\prime} \mathrm{Oz}$ ); Fama (Globo, quatro temporadas, 2002 a 2005, aumentando em $17 \%$ o índice de audiência Ibope para o horário do sábado à tarde); Ídolos (SBT, duas temporadas, 2006 e 2007, e Record, cinco temporadas, 2008 a 2012, derivado do formato britânico Pop Idol e com duas edições para a versão infantil, Ídolos Kids, em 2012 e 2013); The Voice Brasil (Globo, sete temporadas, de 2012 a 2017, desdobrado no The Voice Kids, com temporadas em 2016 e 2017); Super Star (Globo, baseado no formato israelense Rising Star, três temporadas, de 2014 a 2016); e Popstar (Globo, baseado no formato e na experiência de Super Star, primeira temporada em 2017). reality shows de "talentos" (que incluem música, dança, culinária, alimentação, decoração, maquiagem, moda, organização, reforma, entre outros), os modos de dar a ver atores sociais usualmente ausentes nas mídias.

Programas de talentos musicais com a presença de jurados, sobre os quais nos deteremos, são antigos na televisão brasileira. Advindos inicialmente de modelos norte-americanos ou britânicos e integrantes, geralmente, de programas de auditório, com o advento dos reality shows novos formatos foram surgindo. Entre os talentos ligados à performance humana, a habilidade de cantar se consolidou como articulação profícua entre formato, personagens e público. Assumimos, para tal adesão, que o canto envolve a metáfora de expressar-se através da própria voz, sendo a fala de um personagem em seu momento alto. Neste ponto, realities musicais podem ser considerados herdeiros de certa tradição de filmes musicais no cinema e, depois destes, de programas televisivos convencionais. Ademais, considerando o fato de que todos temos uma voz que pode ser evocada e um cancioneiro nacional (ou estrangeiro) comum, a identificação imediata com o espectador completa a articulação para seu alcance mundial. Tais programas conseguem, ainda, acionar valores locais em formatos que favorecem a exportação global de modelos.

Como traço distintivo desses realities musicais, notamos participação mais efetiva do público, que se coloca de modo ativo não apenas por meio de votações ou pela internet, mas também na plateia, na formação de times, na interação com os candidatos e, de forma bastante específica, na presença em cena de convidados, familiares, amigos, que se transformam em personagens e atuam nas gravações, acompanhando não apenas as exibições, mas também seus bastidores. ${ }^{5}$

\section{The Voice Brasil: entre visibilidades e invisibilidades midiáticas}

Ao elegermos o programa The Voice Brasil como destaque dos realities musicais, atribuímos a ele potência narrativa de transformação dos sujeitos apresentados, propondo novas políticas da representação e reencenando sua entrada nos regimes de visibilidade hegemônicos, ainda que, muitas vezes, reinserindo tais sujeitos em dispositivos fortemente marcados. Se a maior presença dos populares na televisão nos parece ser predominantemente conservadora, nem sempre ela mantém esse lugar já estabelecido como estigmatizante, pois no discurso algo sempre se desloca, instaurando significados heterogêneos e espaços polifônicos. Do anonimato ao reconhecimento de pessoas comuns acreditamos haver recodificação e reconfiguração em certos programas televisivos, notadamente aqueles tratados neste artigo. Tal transformação, em grande medida, pode ser atribuída aos hibridismos constituintes de suas narrativas, que apontaremos a seguir.

Em sua quarta temporada, exibida entre 1 o de outubro e 25 de dezembro de 2015, o programa The Voice Brasil contou, durante treze episódios, com a participação de 59 candidatos em sua primeira fase (audições individuais), dos quais 24 passaram à segunda fase (duelos entre candidatos de um mesmo grupo). Na temporada anterior, exibida em 2014, 58 candidatos participaram das audições e 50 passaram para a fase dos duelos. Nas etapas iniciais, pessoas comuns e que geralmente não têm carreiras artísticas regulares ou consagradas se apresentam para um júri de quatro integrantes, representantes de gêneros musicais diversos. O perfil dos participantes e suas histórias de vida são importantes na composição dos personagens, que devem se transformar para estar no palco e desempenhar suas performances.

O site do programa traz informações extras sobre o candidato, sua família, seus hábitos, sua popularidade na internet e nas redes sociais. Entre algumas características desse reality (criado pela empresa holandesa Endemol), nos diferentes países em que é exibido notamos a variedade étnica, religiosa, cultural, social, econômica, física, de gênero, etária, entre outras, de seus participantes - 
${ }^{6}$ As versões mais popularizadas do programa são a americana (The Voice) e a britânica (The Voice UK), mas o formato derivou inúmeras outras versões locais a partir do original holandês iniciado em 2010 (The Voice of Holland), entre elas: The Voice France, The Voice India, The Voice Russia, The Voice Portugal, The Voice Arabia. pessoas comuns tornadas incomuns em suas singularidades. ${ }^{6} \mathrm{O}$ fato de, nas etapas iniciais, a voz do candidato chegar antes de sua imagem corrobora a premissa de que não importa quem você é, mas como você se expressa. Nesse sentido, por sua vez, não há espaço para erro, pois a sanção, positiva (pedagógica) ou negativa (punitiva), será dada rigorosamente pelos avaliadores. $O$ bom desempenho ao vivo determina as chances de classificação e seleção e, progressivamente, de aprendizado e notoriedade.

Mesmo apresentando formato recorrente nos reality shows, acreditamos que em The Voice Brasil os participantes, sujeitos ordinários, porém detentores de um dom, são mostrados não como exceção ou exotismo (a exemplo dos programas de auditório tradicionais), mas como amadores em busca de profissionalização por meio do esforço de aprimoramento de suas limitações em aulas, ensaios, contato com especialistas, conselhos, avaliações técnicas. Ainda que geralmente não estejam presentes valores estéticos ou políticos em relação à arte - e que as músicas escolhidas façam parte de um repertório previamente compartilhado e, nesse sentido, não autoral -, o outro implicado no palco não se coloca como destituído de sua subjetividade, tampouco aceita ser tratado com benevolência ou piedade.

A lógica integradora do mercado e da indústria musical se fazem presentes, pois o que se visa é a adesão; mas a construção da representação do outro não se dá como em programas que buscam talentos antes insuspeitos, nos quais surpresa e destaque surgem, justamente, no reforço ao estigma sob a égide da superação. Em vez de se mostrarem como alheios ao mundo da fama e improváveis em uma carreira enquanto artistas, os participantes do The Voice Brasil parecem romper, na apresentação de músicas de diversos gêneros (samba, sertanejo, MPB, rock, soul, entre outras), certa estratificação de gosto que demarca as classes sociais, ampliando fronteiras musicais ainda que reafirmando sua inserção na indústria.

De toda a extensa estrutura da competição, que segue ordem de fases eliminatórias até que se eleja o artista vencedor, destacamos o momento em que os candidatos se colocam para a primeira apresentação, bem como o momento das decisões eliminatórias. Trata-se de percurso que começa com as "audições às cegas", fase que inclui o maior número de participantes, para se desdobrar em outras etapas. Na segunda fase, os selecionados disputam em "batalhas" dois a dois, nas quais um é eliminado. A edição nacional inclui uma "rodada de fogo", já com participação de votação da audiência, equivalente aos "knockout rounds" presente em versões estrangeiras. Os candidatos restantes passam para a fase de transmissões ao vivo, com "shows" individuais e provas seletivas com votação do público, até o momento do episódio final. Cada momento decisivo é privilegiado no programa como forma de configuração de um julgamento sobre o participante. Tal julgamento, estando em aberto, pode conter características identitárias e apontar para a inserção e/ou deslocamento dos sujeitos que se encontram no centro do palco.

No momento em que é necessário decidir binariamente entre manter ou não um candidato, permitindo que prossiga na competição, há uma confluência complexa de fragmentos que ecoam cenas anteriores. O momento das primeiras audições é aquele de instauração da expectativa sobre os candidatos, dos quais ainda se sabe pouco. Eles são apresentados por meio de vídeos curtos, em forma de testemunhos biográficos cobertos por cenas de seu cotidiano, que narram brevemente suas vidas e justificam sua presença no palco do programa. Esse é o momento encenado de um talento apenas suposto que, por sua vez, ganha proeminência e permite ao público processo de identificação com a imagem dos futuros artistas. Trata-se de uma cadeia de pessoas que suspostamente se apresentam como elas mesmas e reiteram elementos agregados ao reality, compondo uma miríade que responde não apenas ao individual, mas também ao coletivo, aos gêneros musicais, às 
distinções de profissões, etnias, gerações, entre outras. A presença variada dos candidatos também surge como efeito de hibridismos visíveis:

Os eufemismos contemporâneos que, elipsando tensões de diversas ordens, se referem à sociedade como um todo composto de partes adjacentes - maiorias e minorias sociais, categorias socioprofissionais, grupos de interesses e comunidades - vêm, então, perdendo sua eficácia num momento em que as misturas e as "contaminações" parecem suplantar os exotismos. (FIGUEIREDO, 2012: 105)

O formato de The Voice Brasil favorece, em primeiro momento, a instauração e o desenvolvimento de um percurso para cada candidato, personagem-em-formação durante um relato programado, apresentado a partir de dados de sua trajetória pessoal no momento inicial dos vídeos de perfil. No segundo momento, esses mesmos dados são colocados em diálogo dentro da dinâmica do show: na reação e julgamento dos jurados, no retorno da plateia, na interação com o espectador em contato inclusive pelas redes sociais. Podemos dizer, nesse sentido, que temos personagens em aberto, mas considerando sempre direcionamento dado pela provável constituição de um ser artista.

Esse ideal não é exclusivo do programa em questão, pois estrutura também diversos modelos de realities musicais. O específico em The Voice Brasil é a operação de um novo desdobramento, num nível mais amplo do que aquele dos personagens, ao inserir o ideal de ser artista como algo culturalmente desafiado. Mais uma vez, vamos de um ponto marcado em direção a uma brecha - a imagem esperada de ser um artista acolhido na legitimação do público e na aclamação pelo júri. A aceitação do público endossa a transformação para o estrelato, passando pela mediação oferecida na estrutura do programa. O nascimento do artista é amplamente televisionado, ainda que se possa questionar a aferição de retorno do público e a relevância posterior do participante na cena musical nacional. De todo modo, há um destino proposto e que movimenta a estruturação e reestruturação de identidades no percurso do programa, em que os momentos finais encaminham um fechamento e, em caso de vitória, um novo começo.

Dentre as diversas apresentações de 2014, separamos três exemplos que consideramos emblemáticos para demonstrar essa passagem do anonimato à celebrização, de forma distinta em cada caso. Em seu percurso, novas narrativas são somadas àquelas do momento inicial, transformando também as representações e visibilidades propostas ao público. Consideramos que, ao se transformar em personagem, cada participante carrega uma multiplicidade de posições identitárias. Ainda que a imagem de alguns deles possa ser percebida como mais ou menos hegemônica, tal lugar pode ser modificado justamente devido ao deslocamento metonímico que combina a habilidade do candidato em cantar ao fato de os jurados não poderem ver sua imagem nas primeiras audições, ensejando pequenos acontecimentos naqueles minutos iniciais.

É importante ressaltar que, ao contrário dos jurados, o público conhece o participante por meio dos vídeos biográficos, usualmente denominados como "perfil". Desse modo, no momento da audição temos, para os telespectadores, uma espécie de reconhecimento de alguém que já havia sido apresentado. Podemos dizer, de maneira geral, que os vídeos de apresentação no The Voice Brasil procuram ressaltar uma questão polêmica proposta na imagem do candidato, seja em relação a sua trajetória de vida ou a seus posicionamentos pessoais. Os exemplos escolhidos fazem parte de vídeos que registram o momento da primeira canção interpretada pelos candidatos (na fase de "audição às cegas", ou "blind auditions", logo após os vídeos de "perfis"), representativos de sujeitos que respondem a formas plurais de representação, nos termos do que temos buscado neste artigo. 
${ }^{7} \mathrm{Cf}$. vídeo com trecho da audição disponível no canal YouTube do The Voice Brasil (THE VOICE..., 2014a).

${ }^{8} \mathrm{Cf}$. "Surpresa! Deena Love encanta técnicos e entra para o time de Lulu" (SURPRESA!..., 2014).

${ }^{9} \mathrm{Cf}$. vídeo com trecho da audição disponível no canal YouTube do The Voice Brasil : (THE VOICE..., 2014b).

${ }^{10} \mathrm{Cf}$. vídeo com trecho da audição disponível no canal YouTube do The Voice Brasil (THE VOICE..., 2014c).
A primeira participante, Deena Love, ${ }^{7}$ apresenta-se com seu nome artístico, que cria a expectativa de uma figura feminina. Seu vídeo é um dos raros casos em que, na divulgação on-line, o vídeo de apresentação não aparece somado àquele da encenação musical. A presença da candidata é introduzida sem que se veja seu rosto, o enquadramento mostra pernas chegando ao palco, mostrando o detalhe da barra de sua saia. Temos sua voz em off dizendo "Se eu disser que a Deena Love é apenas um personagem para mim estaria sendo muito leviano. É o momento de apoteose do cantor Pedro Novas". Sua encarnação no palco é, assim, mais do que o personagem disponível para a câmera e para o show, é a abertura de algo que escapa ao esperado e foge da categorização fácil.

Podemos entender sua participação como marcada pelo viés do espanto, uma espécie de suspensão do percurso identitário que intentamos aqui descrever. Uma das publicações oficiais do vídeo da audição de Deena Love segue com um texto que tenta determinar um lugar de partida mais demarcado para a candidata e, de alguma forma, suprir a abertura apresentada nas imagens do vídeo. "Deena Love é o personagem criado por Pedro Figueiredo para homenagear as divas da música. Cantor, compositor e percussionista, ele começou a estudar canto aos 17 anos. Aos 20, foi cantar em cruzeiros por todo o mundo. De volta ao Brasil desde 2013, canta na noite paulistana na companhia do pai, também músico". ${ }^{8}$ Em nome de uma abertura lógica, voltamo-nos à comoção durante sua audição, causada pela voz, e acompanhamos quando um dos jurados se emociona com o efeito daquela presença no palco iluminado da televisão, autenticando seu modo de cantar e selecionando-o para ocupar, como competidor por ele escolhido, um dos grupos do programa.

Outro personagem que ocupa esse lugar é Gabriel Silva, ${ }^{9}$ um homem mais velho do que a média etária dos candidatos, cantor de blues que interpreta no palco uma música em inglês, despertando a atenção dos jurados. $O$ vídeo de seu perfil, como acontece na maioria das audições, inicia-se com sua chegada ao estúdio do The Voice Brasil, acompanhado de familiares e amigos. Em seguida, temos uma conversa sua com a apresentadora Fernanda Souza, anfitriã do programa durante a temporada. Gabriel define-se como cantor de blues: "A influência da música negra é muito forte em mim, obviamente. É uma raiz". Na obviedade interpretativa que atribui à própria imagem há uma abertura para os estilos musicais que anuncia. Tal narrativa contempla a identificação com uma história de lutas e com uma cultura estrangeira somada ao percurso feito pelo candidato ao longo do programa. Gabriel refere-se à sua participação dentro da ludicidade da realização de um sonho de menino, no qual pode operar esse ideal artístico de si.

O terceiro personagem destacado, Twyla, ${ }^{10}$ não atende ao ideal estético vigente, e seus figurinos mostram tatuagens e expressões ligadas, de alguma forma, ao gênero rock'n'roll. $O$ vídeo de seu perfil, diferentemente de outros, não se inicia com sua chegada ao estúdio, mas com fotos que podem ser identificadas como retratos de artistas. São poses e enquadramento que instigam sobre a retratada e apresentam, ainda, associação a elementos musicais. A candidata declara gostar muito de soul music e utiliza sua voz para denotar essa escolha. A imagem de um microfone tatuado em seu corpo aparece em várias cenas. "O bom de ser gordinha é que cabe um monte de tatuagem", diz, e em seguida gargalha. Seu corpo é, assim, mostrado nas imagens e referenciado em sua fala. O corte para o momento da apresentação passa do riso forte à emissão aguda no início da música, inserindo-a dentro de um estilo específico. 


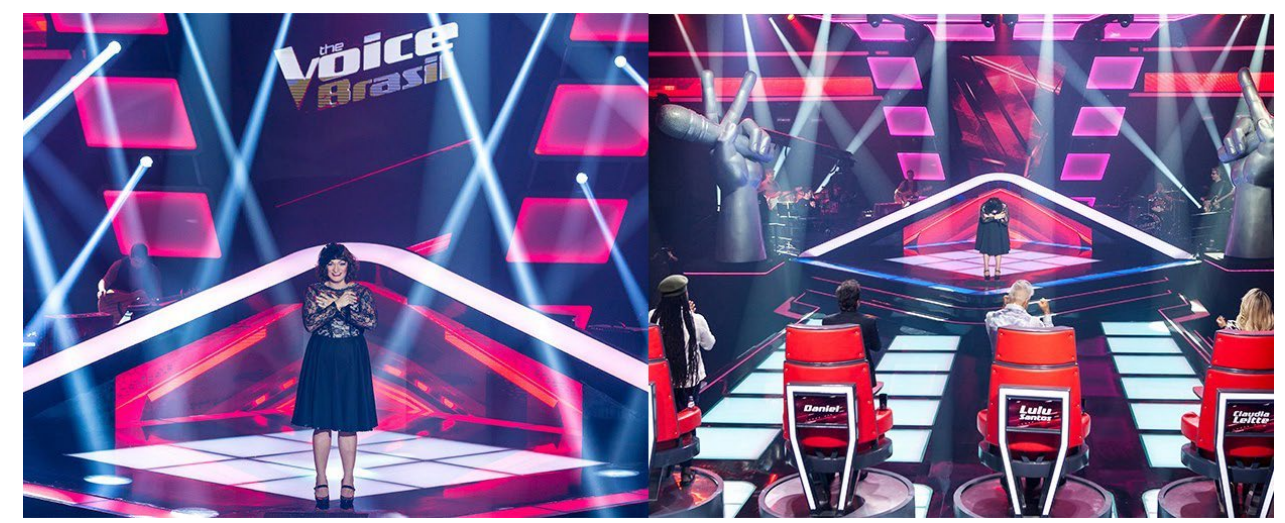

Figuras 1 e 2: Deena Love (SURPRESA..., 2014)

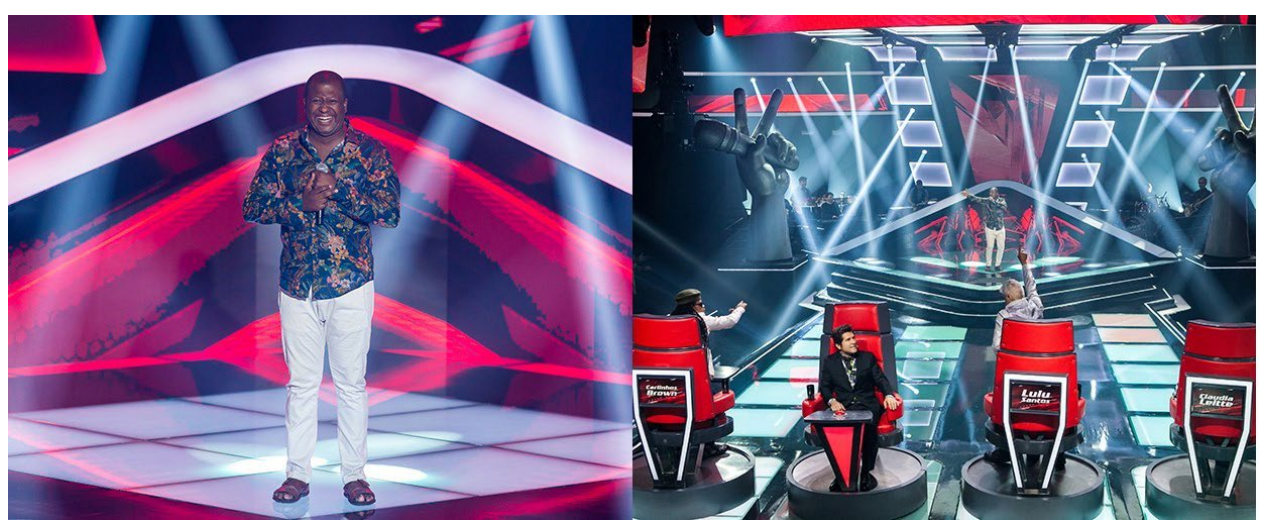

Figuras 3 e 4: Gabriel Silva (GABRIEL..., 2014)

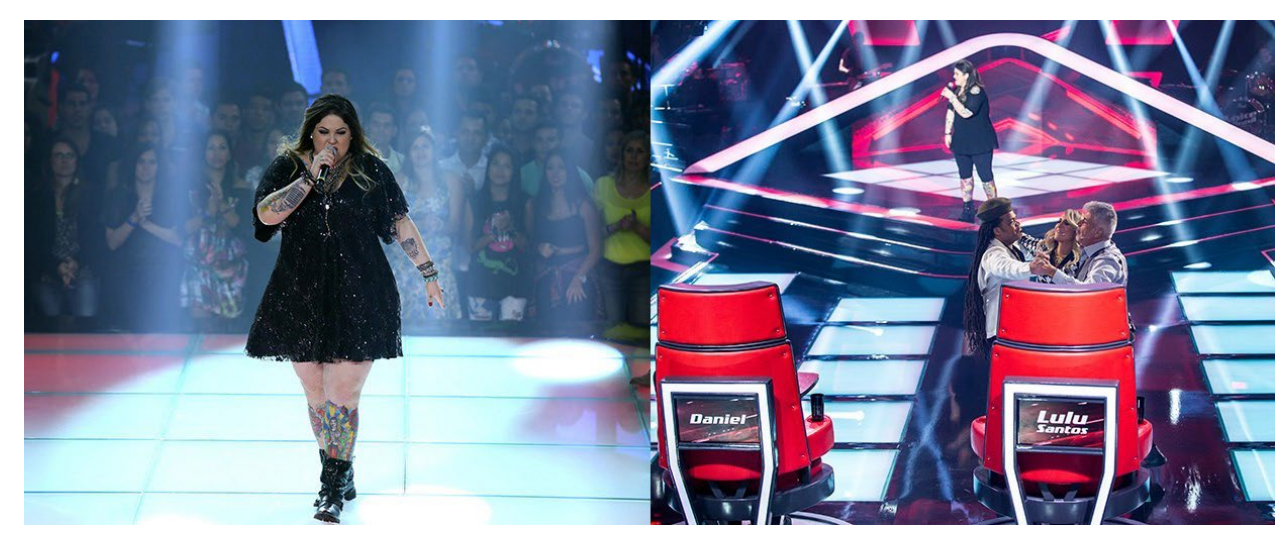

Figuras 5 e 6: Twyla (TWYLA..., 2014)

Podemos dizer que, nos três casos apresentados, há algo de inusitado nas vozes ouvidas, que se percebe mesmo estando ainda dissociadas dos corpos dos sujeitos que cantam, separação que gera fator inesperado quando, após virar as cadeiras, os jurados deparam com os participantes materializados no palco, confirmando o estranhamento sonoro inicial. A trajetória dos cantores vai aproximando o que constroem como identidades possíveis e o que a elas se agrega, por intermédio das visibilidades disponibilizadas pelo programa, na baliza com os parâmetros sedimentados para o ser artista - processo que se completa com o reconhecimento do público. Em geral, o resultado das votações dentro da competição, especialmente em seus momentos finais, acaba por levar em conta as aberturas criadas pelos candidatos ou candidatas e as possibilidades de se inserir numa cultura midiática de valorização do estrelato por meio de aclamação popular.

Como exemplo recente e significativo, citamos a vitória da cantora Alisan Porter na décima edição norte-americana do The Voice (2016), primeira mulher a vencer a competição, também pela primeira vez conquistada por uma mulher na posição de mentora da candidata (Christina Aguilera). Sua aclamação significa o ingresso 
em um intrincado mercado simbólico reproduzido pelo programa, em que os lugares de destaque podem ser ocupados por alguém com talento vocal e carisma pessoal. Eles não estão tão fechados a ponto de não poder receber uma mulher que, em sua trajetória de vida, encontrava-se distante do que se imagina ser a vocação artística mas que, ainda assim, pode ser admirada pelo público e por ele reconhecida, chegando à consagração na narrativa do programa.

Ainda que nos exemplos tratados a voz ensaiada não seja unicamente aquela do sujeito em cena, mas também a voz do programa que se instaura em estratégias narrativas que, no caso da televisão, incluem seleção, roteirização, edição e exibição, notamos a possibilidade de reversibilidade quando, no movimento das cadeiras, 0 personagem elege seu técnico. Na realidade genérica trazida pelos reality shows, referencialidade e ficcionalidade se hibridizam para, em alguns momentos, gerar outra narrativa, na qual atores sociais antes invisibilizados ou silenciados parecem ser incluídos nas representações midiáticas. Se considerarmos, a partir de Rancière (2005), certo "modo de visibilidade" que ao mesmo tempo integra e distingue os atores sociais, podemos arriscar a produção de sentidos advindos dessas imagens televisivas em interação com o espectador. No entremeio dessa construção, percebemos não apenas uma inclusão consentida ou domesticada dos sujeitos ali retratados mas, ao contrário, vislumbramos - ainda que de forma efêmera - rearticulações estéticas e políticas em seus discursos.

Ao problema sobre "como transformar a visibilidade em política efetiva de participação" (RANCIÈRE, 2005), em que esse reconhecimento cruze as demarcações de gosto que separam a suposta alta da baixa cultura e possa interferir na produção discursiva hegemônica perpetrada pela grande mídia, outra questão se impõe: o subalterno corporificado nessas imagens de fato pode falar e ser ouvido? Ou permanece calado frente a vozes hegemônicas? A essas perguntas, que retomam em outro contexto os conceitos de Gayatri Spivak (2010), respondemos com a potência múltipla e incompleta dos discursos, em que desvios e rupturas se fazem presentes. A emergência dos populares na televisão, mote do artigo, pode ser pensada a partir desses questionamentos em relação ao lugar do outro e aos modos de apresentá-lo. Nesse cenário, notamos que a telerrealidade se afirma como principal forma genérica televisiva, ao mesmo tempo em que reality shows se colocam como espaço privilegiado para a mostra dos populares, dos sujeitos comuns, dos anônimos, dos amadores.

Em cada um dos casos analisados, notamos a posição ocupada pelo subalterno em sua outridade e os embates discursivos que o definem. Ainda assim, nem sempre os deslocamentos discursivos serão percebidos de maneira homogênea ou unívoca, ainda que se tratasse de uma voz autorrepresentada nas imagens televisivas. De acordo com Spivak, vale destacar, o subalterno não é qualquer sujeito marginalizado, mas aquele que se encontra "nas camadas mais baixas da sociedade constituídas pelos modos específicos de exclusão dos mercados, da representação política e legal, e da possibilidade de se tornarem membros plenos no extrato social dominante" (SPIVAK, 2010: 12). Para ela, não se pode falar "pelo" subalterno, mas pode-se falar contra a subalternidade, aprender a falar com ele (e a ouvir sua resposta), desconstruindo lugares tidos como privilegiados e desaprendendo discursos instituídos. Ainda que o subalterno não possa falar se permanecer enquanto tal, pois não seria ouvido, seus modos de constituição precisam ser problematizados, inclusive na recusa à busca de uma possível autenticidade ou pureza em relação a ele.

O processo da fala - e de visibilidade - se concretiza, portanto, pela assunção de uma posição discursiva que acontece em um espaço dialógico entre falante e ouvinte, e essa interação não se concretiza jamais se não houver equilíbrio entre eles. Daí a impossibilidade, segundo Spivak, de se articular um discurso de resistência fora dos discursos hegemônicos e, nesse sentido, a insurgência 
emerge do já conhecido. Além da celebrização ou julgamento identitário ou de gosto, em The Voice Brasil notamos uma aproximação ao sujeito comum, mas já não tão ordinário ou desprovido de voz, concebendo de maneira não dicotômica a estetização midiática e a politização democrática.

Nesse programa, ao perguntarmos se o subalterno pode falar e ser ouvido, respondemos, com Spivak, que sim, desde que sejam instauradas as condições de produção de sua própria fala. Em The Voice Brasil, quando nas audições individuais as cadeiras são viradas e alguém reconhece o sujeito no palco como detentor de uma voz autônoma - a voz de um "outro" - temos uma fala que não cai no vazio e reverbera em alternativas ao já estabelecido, deslocando, ainda que provisoriamente, representações e visibilidades encenadas no ato performativo.

Eis aqui a questão que, finalmente, ensejamos a partir da dinâmica de The Voice Brasil em direção a um debate sobre posições de subalternidade: trata-se de um modo de construção menos estigmatizado, passível de causar novos sentidos? Ou, ao contrário, a caracterização desses personagens como "pessoas comuns" os mantém em seus lugares usuais, como em antigos programas humorísticos, de auditório, vespertinos ou sensacionalistas? Acreditamos que na produção ficcional consolidada, como em telenovelas e minisséries, em alguns momentos podem ser percebidos deslizamentos nas políticas da representação do "outro" (seja ele próximo ou distante), talvez amplificados com a proliferação recente de realities. Em alguns deles, para além dos processos de celebrização, humilhação ou condescendência, percebemos a ampliação dos atores sociais apresentados, alargando as fronteiras entre o idêntico e o diverso.

Programas e personagens televisivos operam, então, uma migração partindo de um lugar de impurezas em direção à concretização de um desejo por visibilidade. Se por um lado tal percurso nutre a indústria midiática, ele também alavanca identidades periféricas ao centro da cena, instaurando vozes dissonantes e, em alguns casos, a possibilidade de serem efetivamente ouvidas. Ao apontar para a urgência de buscar políticas da representação que possam estabelecer novos regimes de visibilidade, torna-se imprescindível interpelar os lugares de silenciamentos identitários e invisibilidades sociais, sejam aqueles performatizados no cotidiano, sejam aqueles encenados pelas mídias, transformando a visibilidade em política efetiva de participação e reconstrução coletiva.

\section{Referências}

ALTMAN, R. A semantic/syntactic approach to film genre. Cinema Journal, Austin, v. 23, n. 3, p. 6-18, 1984.

AUMONT, J. et al. A estética do filme. 9. ed. Campinas: Papirus, 1995.

BAKHTIN, M. Problemas da poética de Dostoiévski. 4. ed. Rio de Janeiro: Forense Universitária, 2008.

FIGUEIREDO, V. L. F. A partilha do espaço urbano e a questão do outro próximo: repercussões no discurso teórico e na fiç̧ão cinematográfica. Revista Galáxia, São Paulo, n. 24, p. 103-114, 2012.

FOSTER, $\mathrm{H}$. The return of the real: the avant-garde at the end of the century. Cambridge, MA: The MIT Press, 1999.

JENKINS, H. Cultura da convergência. 2. ed. São Paulo: Aleph, 2009.

JOST, F. Compreender a televisão. Porto Alegre: Sulina, 2007. 
GABRIEL Silva abre a terceira temporada e garante vaga no time de Lulu. GShow, Rio de Janeiro, 18 set. 2014. Disponível em: <https://goo.gl/WYE9Ao>. Acesso em: 14 nov. 2017.

KELLNER, D. A cultura da mídia: estudos culturais: identidade e política entre o moderno e o pós-moderno. Bauru: Edusc, 2001.

NICHOLS, B. Representing reality: issues and concepts in documentary. Bloomington: Indiana University Press, 1991.

RANCIÈRE, J. A partilha do sensível. São Paulo: Editora 34, 2005.

SAID, E. W. Cultura e imperialismo. São Paulo: Companhia das Letras, 1995.

SALEM, R. Mostra 2014: 'Relatos Selvagens' equilibra pop e inteligência. Folha de S. Paulo. São Paulo, 19 out. 2014. Disponível em: <https://goo.gl/SWjkwT>. Acesso em: 26 nov. 2017.

SAMAIN, E. Antropologia, imagens e arte: um percurso reflexivo a partir de Georges Didi-Huberman. Cadernos de Arte e Antropologia, Salvador, v. 3, n. 2, p. 47-55, 2014. Disponível em: <https://goo.gl/Vc5Nt7>. Acesso em: 14 nov. 2017.

SERELLE, M. A guinada dos populares: mídia e vida social no Brasil. Revista Contracampo, Niterói, v. 30, n. 1, p. 44-59, 2014.

SILVERSTONE, R. Television and everyday life. London: Routledge, 1994.

SOARES, R. L. De convergências e hibridismos: remixagens e pilhagens em filmes de bordas. Revista Matrizes, São Paulo, v. 5, n. 1, p. 137-154, 2011.

Realismos audiovisuais: visibilidades intertextuais em documentários televisivos. Doc On-Line: Revista Digital de Cinema Documentário, Covilhã, n. 18, p. 216-240, 2015. Disponível em: <https://goo.gl/TxcXNN>. Acesso em: 14 nov. 2017.

SPIVAK, G. C. Pode o subalterno falar? Belo Horizonte: UFMG, 2010.

STAM, R. From hybridity to the aesthetics of garbage: the case of Brazilian cinema. Estudios Interdisciplinarios de América Latina y el Caribe, Tel Aviv, v. 9, n. 1, 2015. Não paginado. Disponível em: <https://goo.gl/tN5SYb>. Acesso em: 14 nov. 2017.

SURPRESA! Deena Love encanta técnicos e entra para o time de Lulu. GShow, Rio de Janeiro, 18 set. 2014. Disponível em: <https://goo.gl/4c7coi>. Acesso em: 14 nov. 2017.

TWYLA levanta o público do The Voice Brasil com muito rock ' $n$ ' roll. GShow, Rio de Janeiro, 20 nov. 2014. Disponível em: <https://goo.gl/DZV8UG>. Acesso em: 14 nov. 2017.

WILLIAMS, R. Television: technology and cultural form. New York: Schocken, 1975.

THE VOICE Brasil - Deena Love arrepia no palco. 0'36". The Voice Brasil. YouTube. 2014a. Disponível em: < https://goo.gl/bJxrK8>. Acesso em: 14 nov. 2017.

THE VOICE Brasil - Gabriel Silva abre terceira temporada. 0'36". The Voice Brasil. YouTube. 2014b. Disponível em: <https://goo.gl/5F6Rg6>. Acesso em: 14 nov. 2017.

THE VOICE Brasil - Twyla arrasa com sua potência vocal. 0'34". The Voice Brasil. YouTube. 2014c. Disponível em: <https://goo.gl/iGSTQG>. Acesso em: 14 nov. 2017. 